\section{THE SURGICAL MANAGEMENT OF HIGH GASTRIC ULCERS}

\author{
BY
}

R. MILNES WALKER, M.S.LOND.

HONORARY SURGEON, ROYAL HOSPITAL, WOLVERHAMPTON

(With Special Plate)

In May, 1933, C. A. Wells of Liverpool ${ }^{1}$ described four cases of chronic gastric ulcer, situated high up on the lesser curve of the stomach, which he had treated with most gratifying results by performing a Polya-Moynihan partial gastrectomy, the line of section of the stomach being made below the level of the ulcer, so that the ulcer was left in the remaining portion of the stomach. His first case was operated upon in February, 1930. During the same month, quite independently, Deanesly at Wolverhampton devised the same method of dealing with these cases, and before he retired from the staff of the Royal Hospital, Wolverhampton, in 1931, performed the operation four times. Since then six more examples have been added to this series by myself. These ten cases form the basis of this paper, and I feel that the results certainly justify the line of treatment being given a more extended trial. The series is a short one, but I hope that other surgeons who may have given the method a trial since the publication of the paper by Wells will announce their results so that greater experience may lead to a more accurate estimate of the value of the operation.

\section{The Operation}

In the present series the operation was performed in most cases after the patient had had repeated courses of medical treatment, often as an in-patient, but the symptoms had failed to subside. In two cases the symptoms were of quite short duration, but the operation was advised on account of a suspicion of malignancy. The ages of the patients ranged from 31 to 52 , the average being 43.4 years. There were only two women, both housewives, while most of the men were employed in heavy occupations. The first was operated on six years ago, and the last only nine months before the present report.

In each of these cases the ulcer was situated high up on the lesser curve of the stomach, and was adherent to the liver or pancreas, or both. Excision of the ulcer would have been difficult and attended with considerable risk, whereas a gastro-jejunostomy for these high ulcers does not give satisfactory results. As regards the possibility of malignancy, none of these was considered to be carcinomatous at operation, but, if there is any doubt, a growth in this situation invading the liver or pancreas is not operable, so that the question of its excision does not arise. In every case the operation was performed under general anaesthesia, supplemented by infiltration of the intercostal nerves and splanchnic plexus with novocain.

The type of operation was the Polya-Moynihan method, the anastomosis being antecolic, with the afferent loop of jejunum at the greater curve. In one case a retrocolic anastomosis was performed, because the fixation of the ulcer to the liver prevented an anterior anastomosis unless a very long afferent loop was made. Silk suture material was used in the earlier cases, but catgut has been employed in the last half of the series. There was no mortality from the operation, and no serious complications.
Results

One of the series (Case 2) cannot be traced. The patient last attended his panel doctor four years after his operation, but his doctor having left the district we have not been able to find out what his condition was then. Another patient (Case 4) received no benefit from the operation. In addition to her gastric ulcer she suffered from gall-stones, and her gall-bladder was removed at the same time. The gall-bladder was probably responsible for most, if not all, of her previous symptoms, so that the case can hardly be considered a fair test of the operation on the stomach. She has not been up for examination, but her doctor has kindly sent a report regarding her condition.

The remaining eight patients are all on full work. There is no complaint of any symptoms except slight feeling of fullness after meals. Seven of these have been examined recently, and six were submitted to a barium meal and $x$-ray examination. The eighth patient, who lives twenty miles away, has been interviewed by his own doctor, who has kindly furnished a report. Of the six who were recently examiñed radiologically five showed no sign of an ulcer; the sixth, who has no symptoms, shows slight scarring at the site of the ulcer, with a little spasm of the greater curve.

It may be claimed, therefore, that among the nine patients who have been followed, eight can be regarded as clinical cures. Most of them eat whatever food they desire, smoke a moderate number of cigarettes, and take a reasonable quantity of alcohol without its bringing on indigestion. They have been able to follow their occupations without interruption from gastric trouble since their post-operative convalescence was completed; the period of time since their operations is nine months in the most recent to over six years in the earliest.

\section{Case Reports}

Case 1:-A coal miner, aged 31, had had pain for one year, and three severe attacks of haematemesis. At the operation on February 27th, 1930, an ulcer was found high up on the lesser curve. A report from his doctor, dated June 9th, 1936 , states: "Condition satisfactory, no complaints; still thin, but not losing weight; eats practically anything, feels fitter than he has ever done; no vomiting, except when he drinks too much beer; smokes a lot; has been at work continuously since recovery from the operation."

Case 2.-A miller, aged 36, had had a three-years history. At the operation on March 24th, 1930, a small, deep indurated ulcer was found high up on the lesser curve. $\mathrm{He}$ attended his panel doctor in 1934, but has been untraced since.

Case 3.-A male spinner, aged 49, had had one year's history, including a course of in-patient medical treatment. The $x$-ray report indicated the presence of a gastric ulcer high up in the lesser curve. At the operation on January 12th, 1931, the $x$-ray findings were confirmed. On June 3rd, 1936, it was reported that he had been at work in a spinning shop continuously since his operation, except when he had pneumonia two years previously. He can eat anything; the weight keeps constant; he drinks beer, and smokes fifteen cigarettes a day. There are no symptoms.

Case 4.-A housewife, aged 50, had had a two-years history of -indigestion with attacks of biliary colic. The $x$-ray report was that there was a gastric ulcer high up on the posterior surface. The operation was performed on June 18th, 1931, and was associated with a cholecystectomy for gall-stones. Her medical practitioner reported on June 4th, 1936: "She is very emaciated, has frequent attacks of vomiting and pain, and can only take just enough nourishment to keep her going."

Case 5.-A male planisher, aged 50, had had a six-weeks history of pain and vomitıng. The $x$-ray examination showed a high posterior excavating gastric ulcer. At the operation on March 3rd, 1933, a large indurated ulcer was found high 
up on the posterior surface; the stomach was very large. His condition on June 3rd, 1936, was: weight stationary ; no pain or indigestion; he can eat anything; smokes twelve cigarettes a day, and drinks stout. He has been at work ever since the operation. The $x$-ray report was: "Still large stomach, empties rapidly ; no sign of ulcer."

Case 6.-A retired photographer, aged 52, had had Finney's operation for pyloric ulcer in 1925 ; there was recurrence of pain for two years. The $x$-ray report indicated delayed emptying, and a suspicion of recurrence of the pyloric ulcer. The operation on October 9th, 1934, disclosed a large saddleshaped ulcer high up and adherent to the pancreas. The condition on June 3rd, 1936, was reported as: "No indigestion ; can eat anything, slight fullness after a heavy meal ; has put on 1 st. 3 lb." The $x$-ray examination indicated a rapidly emptying stomach, and no sign of ulcer.

Case 7.-A housewife, aged 36 , had had a two-years history. The $x$-ray report showed the presence of a large gastric ulcer on lesser curve, half residuc after four hours. Weight 6 st. At the operation on January 11th, 1935, a large saddle-shaped ulcer was found on the lesser curve, penetrating the liver and pancreas. Her condition on June 3rd, 1936, was: "Can eat anything, and does her housework; no indigestion, and a feeling of fullness only after eating bacon." Weight $8 \mathrm{st}$. $5 \mathrm{lb}$. The $x$-ray examination revealed some scarring at the site of the ulcer, with some spasm on the greater curve.

Case 8.-A blacksmith, aged 44, had had a six-weeks history. The $x$-ray examination showed a large ulcer on the lesser curve (Fig. 1 on Plate). The operation on January 11 th, 1935, disclosed a large ulcer on the lesser curve and posterior surface, penetrating the pancreas. His condition on June 3rd, 1936, was: "Weight stationary; no pain, but feeling of fullness after meals; eats anything. Smokes ten cigarettes a day, drinks stout." Has worked as a blacksmith without interruption since April 8th, 1935. The $x$-ray report was: "About half stomach remaining, some sagging below the anastomosis; no sign of ulcer, and no delay in emptying." (Fig. 2 on Plate.)

Case 9.-A crane driver, aged 37, had had an eight-years history of indigestion. The $x$-ray film revealed a large excavating ulcer on the lesser curve (Fig. 3 on Plate). At the operation on July 5 th, 1935, a large ulcer was found high up on the lesser curve, with induration extending almost to the cardia. His condition on June 3rd, 1936, was: "Has gained $3 \mathrm{lb}$. in weight; a feeling of fullness after meals passes off in ten minutes; eats most things, but has kept off pork. Smokes ten cigarettes a day, and takes alcohol occasionally ; at work continuously since September 30th, 1935.' The $x$-ray report was: "Stomach empty in a few minutes; no sign of ulcer" (Fig. 4 on Plate).

Case 10.-A male fitter, aged 49, had had a fifteen-months history of indigestion. The $x$-ray report revealed a large excavating ulcer on the lesser curve. At the operation on October 1st, 1935, there was found a large ulcer on the posterior wall near the cardia, penetrating the pancreas. His condition on June 3rd, 1936, was: "No indigestion or feeling of fullness; has put on 1 st. $3 \mathrm{lb}$., and been at work since he resumed after leaving hospital; is careful with his diet, avoiding pork and much coarse meat. Smokes three cigarettes and takes one bottle of stout a day." The $x$-ray film showed rapid emptying and no sign of ulcer.

\section{Summary}

A short series of cases is recorded in which a partial gastrectomy below the ulcer was performed for high gastric ulcers on the lesser curve, the ulcer being left in situ. Out of nine patients who have been traced, eight can be regarded as cured ; they are leading normal, active lives, having no symptoms or only a little feeling of fullness after meals.

I owe a debt of gratitude to Mr. E. Deanesly, F.R.C.S., not only for permission to report on his cases, but also for introducing me to this and many other practical surgical procedures. I also wish to thank Dr. G. E. Dyas for the radiographs, and Drs. C. L. Spackman and C. A. Hodges for their help in reporting on some of the patients.

Reference

'Wells, C. A.: "High Gastric Ulcer: a Suggested Operation," British Medical Journal, 1933, i, 778 .

\section{DIVERTICULA OF THE STOMACH A REPORT OF TWO CASES}

\author{
BY
}

REGINALD T. PAYNE, M.S., M.D.LoND., F.R.C.S. CASUALTY SURGEON, ST. BARTHOLOMEW'S HOSPITAL (With Special Plate)

The subject of diverticula of the stomach was reviewed by Rivers; Stevens, and Kirklin ${ }^{1}$ of the Mayo Clinic in 1935. These authors state that 141 cases had been recorded in the literature up to the date of their paper, the majority being since the introduction of radiology of the stomach and many lacking pathological confirmation. The following classification is suggested by the above authors for the purpose of analysing the various types of gastric diverticula:

1. True Diverticula.-Those in which the pouch includes all coats of the gastric wall without definite evidence that organic disease was the causative factor. Such diverticula Frobably are congenital.

2. Acquired, True Diverticula.-In these all coats of the gastric wall are present, although there may be some thinning, and there is evidence that some disease was instrumental in causing the pouching.

(a) Pulsion type diverticula result from intragastric pressure, which is probably localized.

(b) Traction type diverticula are incidental to extragastric adhesions.

3. False Diverticula or Diverticula Formations.-In these there is a break in the gastric wall resulting from disease.

The authors above quoted record in their paper fourteen cases of true diverticulum of the stomach. Pathological confirmation was carried out in all these cases, ten of the diverticula being removed at operation and four at post-mortem. The site distribution of these fourteen cases was as follows:

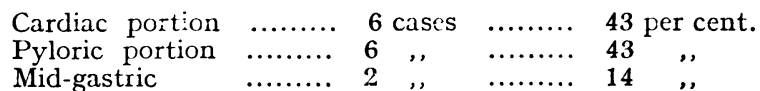

\section{Case Records}

The two gastric diverticula now reported were removed at post-mortem at St. Bartholomew's Hospital, and the specimens are in the museum of the medical college. They are reported as examples of a rather unusual condition, but one which is likely to be encountered more frequently in the future as the result of the increasing use of radiology in the investigation of gastric disease.

\section{CASE I}

The specimen was removed at post-mortem from a woman of 44, who died following cholecystectomy. For some twelve years she had suffered from severe attacks of abdominal pain, which had at times been followed by jaundice. There was nothing in the symptomatology to suggest that the patient had ever suffered in any way from the presence of a gastric diverticulum. At operation the gall-bladder was found to be chronically inflamed and to contain many small calculi. Postmortem examination showed an extreme degree of atrophy of the thyroid and of the suprarenal cortex, and these changes were probably responsible for death twelve hours after operation.

The specimen is in the museum of St. Bartholomew's Hospital Medical College, No. K.136. The diverticulum (Fig. 1 on Plate) is situated on the greater curvature of the stomach about one inch below the cardiac orifice, and is one inch in length and one inch in width, and its orifice is threequarters of an inch wide. It is extremely thin-walled, and the level at which the gastric muscle surrounds it can be made out. The rest of the stomach is natural.

Microscopically the wall of the diverticulum is lined by rather flattened epithelium, usually only one layer thick and 
R. MILNES WALKER : SURGICAL MANAGEMENT OF HIGH GASTRIC ULCERS

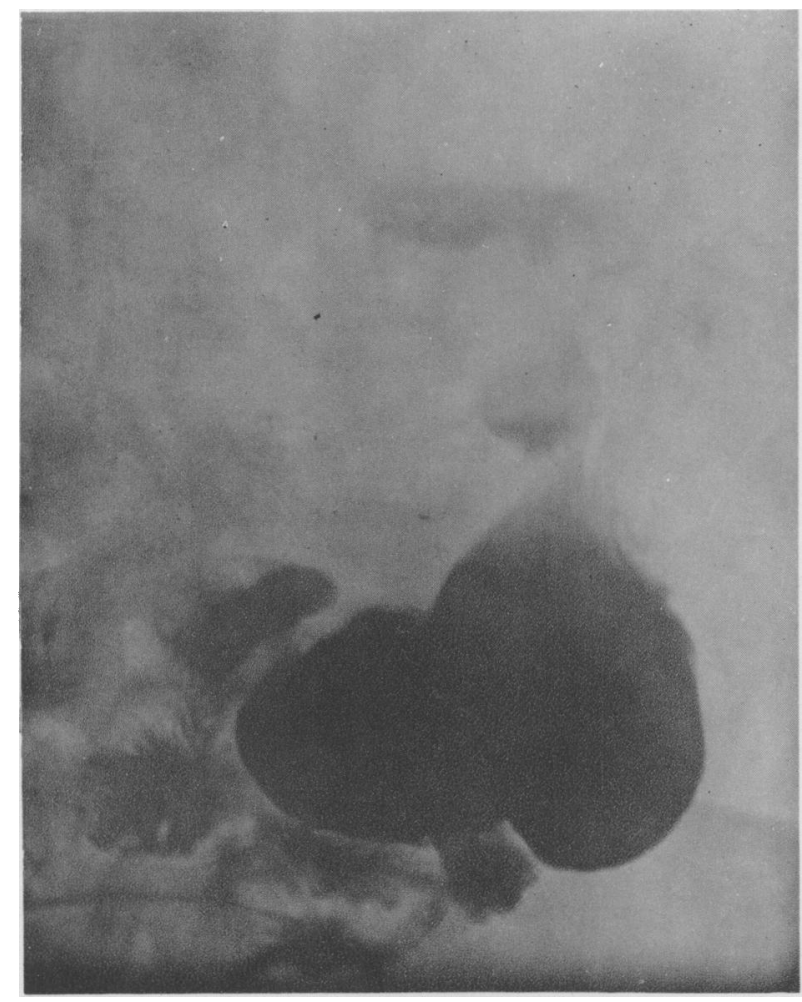

Fic. 1.-Case 8. Before operation.

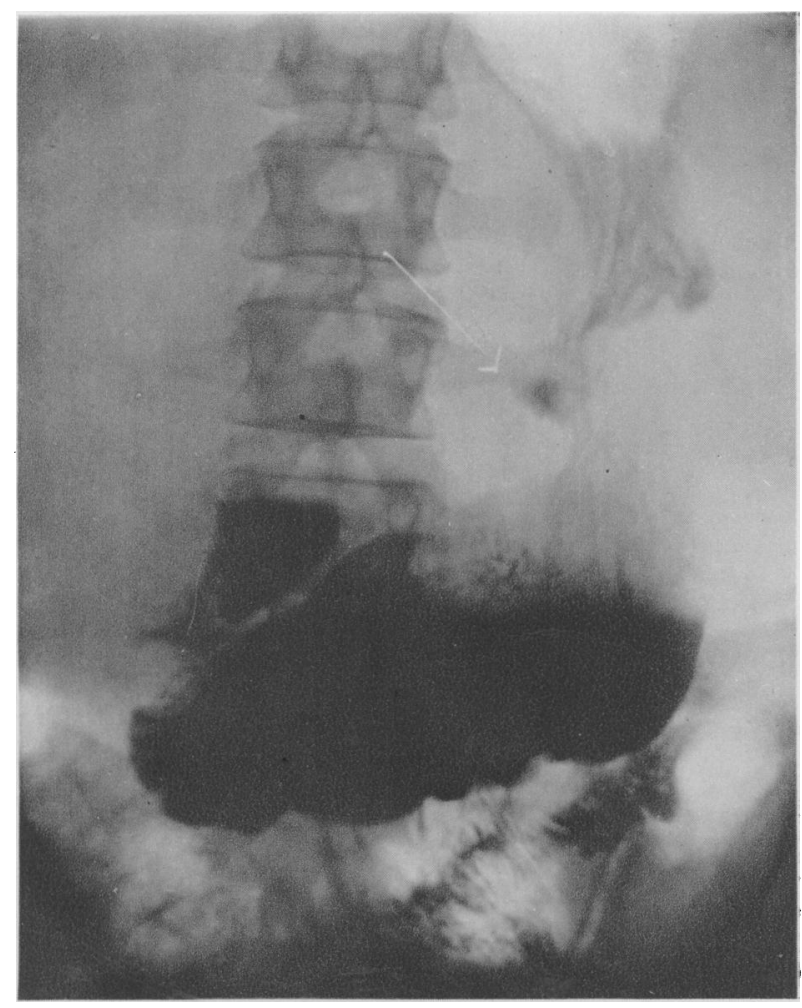

Fia. 3.-Case 9. Before operation.

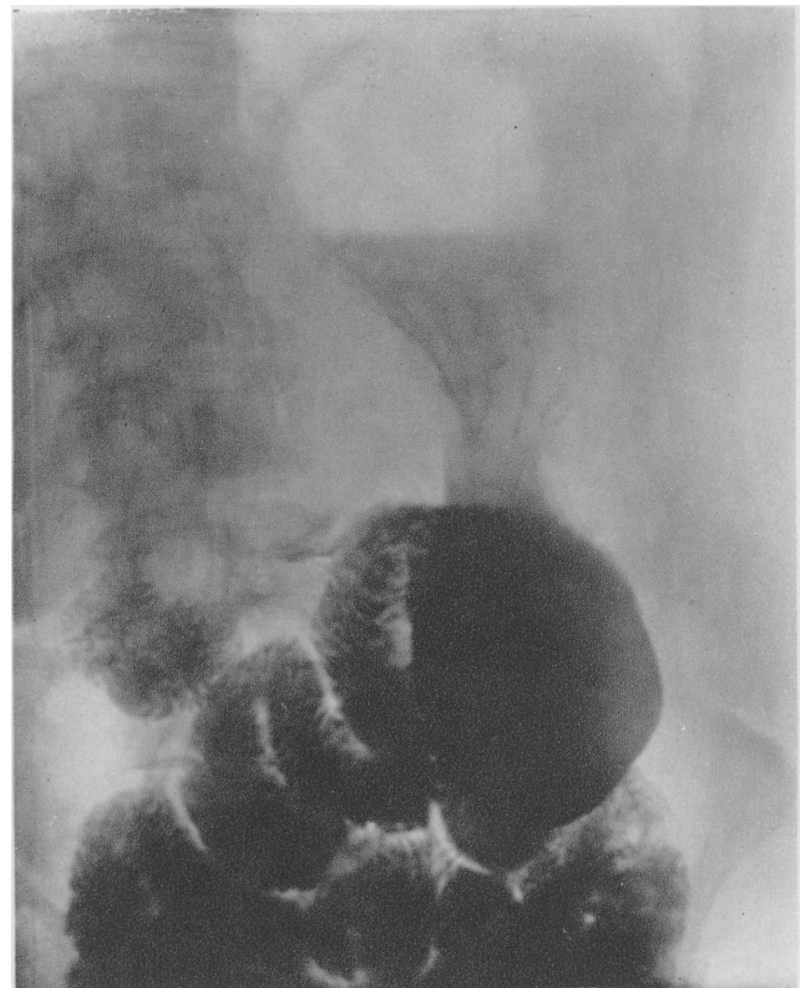

Fif. 2.-Case 8. Seventeen months after operation.

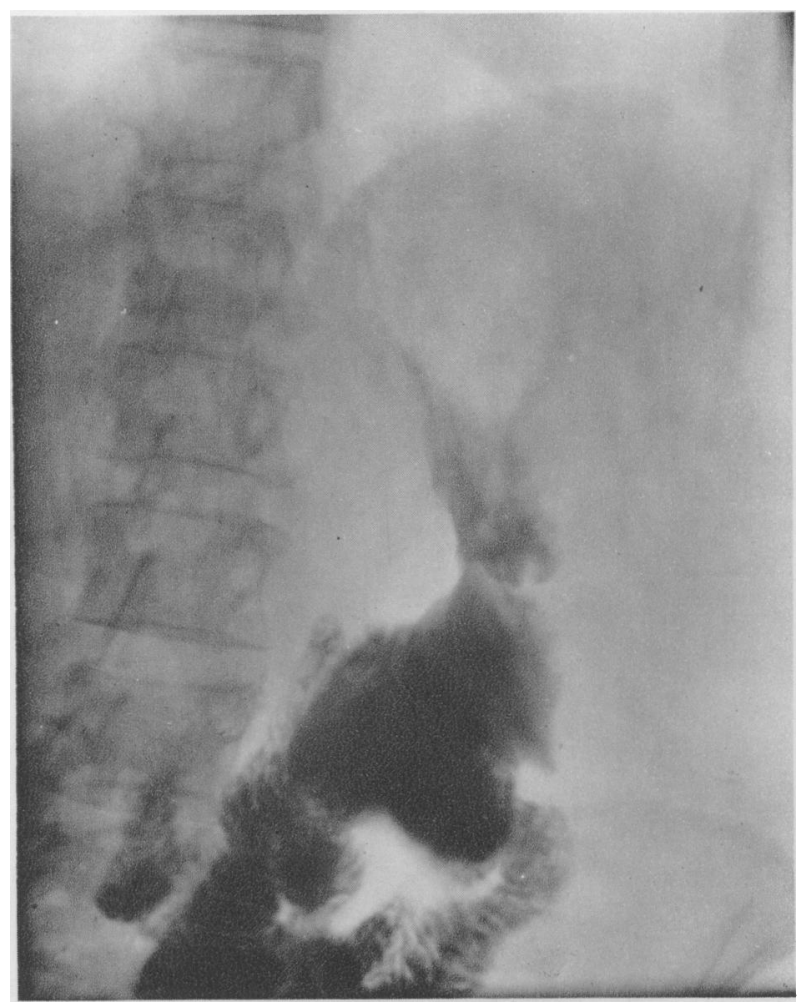

Fia. 4.-Case 9. Eleven months after operation. 